\title{
A SNAPSHOT OF STRATEGY RESEARCH 2002-2006
}

\section{Andy Adcroft (University of Surrey) and Robert Willis (Anglia Ruskin University)}

\section{Introduction}

The aim of this paper is to examine the philosophical underpinnings of, and contributions to knowledge made by, research in the field of strategy in the five year period between 2002 and 2006. The argument the paper proposes is two fold. First, strategy research is dominated by a positivist philosophical underpinning and, second, strategy research rarely makes any significant theoretical innovations. In making these arguments, the paper has been organised into four sections. The first section examines a number of issues about management research and knowledge creation. In particular, the section presents a conceptual model of the process of management research derived from the discussion of philosophy, purpose, approach and outcome preceding it. The second section presents evidence from 23 journals and almost 4,000 research articles from the field of strategy which examine the philosophical underpinnings which influence how research is carried out and the types of outcome which strategy research generates. The third section discusses these findings in terms of this study specifically and in terms of the wider issues raised about the value of strategy research from the literature. The final section concludes the paper by considering the limitations of this study and identifying the key lessons from the theory and evidence contained within it.

\section{Philosophies, purposes, processes and outcomes of management research}

The historian E. H. Carr suggested that to truly understand history, and why things are as they are, one needs to examine the philosophical and ideological discourses which underpin them. In possibly over simplistic terms, Carr's argument was that historical events and the things that happened are important as illustrations of the philosophical and ideological battles of the time. Progress, for Carr and likeminded historians, was the product of high level debate between ideas more than anything else. Whilst this may have revolutionised the teaching of history in British universities in the 1960s, this was not a new idea as it has origins in both the social and natural sciences. Biology, for example, offers the concept of trophic cascade which explains the impact when there is domination by one species. The first effect is that lesser species diminish in number as the dominant species kills them off and this is then followed by degeneracy within the dominant species as it becomes introverted before eventually wasting away. The biological imperative, therefore, is for diversity as that is what drives evolution, change and advance. This argument finds reflection in social science first through Hegel and later through Marx who also suggested that advances are made through dialectic activity which establishes a truth between thesis and antithesis. If advances in nature and politics are driven by such conflict, we would argue that it is reasonable to expect a similar thing in strategy research; the current form and content of strategy research is a product of the philosophical debates which underpin it. 
We begin, therefore, with a brief discussion of philosophies of management research. This is the logical starting point because philosophy (be it implicit or explicit) has a fundamental influence on the purpose of management research and, subsequently, the approach taken to management research. Usunier (1998) identified two general philosophies of research, positivist and phenomenological, and argues that whichever philosophy most closely reflects the predilections of the researcher will have the biggest influence on the choice of methodology. Positivists, argue Noblitt and Hare (1988) "seek cause and effect laws that are sufficiently generalisable to ensure that a knowledge of prior events enables a reasonable prediction of subsequent events" (p.12). This reflects a particular set of beliefs, based around the notion of the world as being external to the researcher, where objectivity is achieved as the researcher is absolutely independent of that being observed. This stands in stark contrast to the phenomenological view of the world as being socially constructed whereby the researcher is necessarily a part of that which is being observed.

Differing views of the world inevitably lead to differing views on how that world can be analysed and understood. Quinton and Smallbone (2005) compare the two philosophies and suggest that "positivist management research is based on empirical social science methods" with an emphasis on "validity, reliability and generalisation" (p.301). On the other hand, phenomenological management research stresses the "trustworthiness and authenticity" of each individual study and a "shared understanding" between researcher and subject (p.303). Painting with a reasonably broad brush, Fawcett and Hearn (2004) sum up the position by arguing that "phenomenological approaches are often associated with qualitative orientations and positivist positionings with quantitative techniques" (p.205-206).

Just as there are opposing philosophies of management research, so too are there competing arguments as to the purpose of management research. The playwright and poet Freidrich von Schiller, for example, suggested that there are two types of academic. On the one hand were those with "philosophical minds" whose purpose was to generate new ideas and discoveries solely for the sake of extending knowledge, people later described by Ayer (1968) as "humanists". On the other hand is a second group of academics, those who Schiller described as "bread learned", for whom the activity of research is aimed at delivering knowledge that has some kind of practical worth and value. For example, Hakala and Ylijoki (2001) suggest "traditional academic research is giving way to new forms of knowledge production" and "a purely basic research orientation is being replaced by working with problem orientated applications". Whilst our discussion of management research begins with these extremes, we recognise that the motivations which drive academic research will differ from project to project and researcher to researcher and that most research will be driven by a purpose somewhere between the two.

In reviewing six major studies of academic research, Vermunt (2005) concluded that there are a number of different motivations behind research which has, thus, created many different types. The first type of research reflects the humanist tradition of academia and is based around exploration and discovery. In discussing this type of 
research, Collins (1993) suggested that most knowledge generated by social scientific research is really transformed knowledge rather than created knowledge. This transformation involves a starting point of "symbol type knowledge" which is individual and context specific and the aim is to create "encultured knowledge" which moves knowledge from the specific to the general and allows it to reach a wider audience. This notion of reaching a wider audience is important to writers like Shugan (2003), for example, who suggest that successful knowledge creation depends on the constituency; "one of the best ways to interest an audience is to have a significant impact on that audience" by having something original to say (p.1). The notion of impact is a recurring theme in the literature and can apply as much to the re-examination of existing knowledge as to the creation of new knowledge. For example, in the specific case of strategy research, Baldridge et al (2004) argue that "academics and practitioners both value research that is interesting - in the sense that it questions basic assumptions and beliefs - and justified - in the sense that its claims are well supported by evidence" (p.1064).

At the other end of the spectrum, Vermunt suggests that research can have a much more utilitarian purpose. For example, Shugan is again useful and he argues that "business schools subsidise research both to help the advancement of knowledge and also because subsidisation has traditionally been in their own self interest ... reputation is critical for most, if not all, revenue sources" (p.3). This instrumental perspective is reinforced by Bergh et al (2006) who discuss the impact of articles published in the Strategic Management Journal. They conclude that this is crucial because "reviewers and editors can use the findings for gaining more insight into their important decisions about what appears" and, within business and management schools, administrators will be able to "make more informed decisions regarding promotions" (p. 97). In this framework the purpose of research is as much career progression as knowledge creation. This view of research as having a value for the researcher and their institutions was also developed by Podsakoff et al (2005) who suggest that a failure to treat research in this manner will "distort resource allocation decisions" (p.488).

Research can also have a value outside of academia. Cordell et al. (2006) damn with faint praise by making the point that "although academic research is often obtuse and unrealistic, many articles have implications that have relevance to the real world inhabited by practitioners" (p.78). This view is a reasonable reflection of the relationship between knowledge and action. Schreyogg and Geiger (2007) define knowledge as something which "covers more or less all features that may enable and enhance effective action" (p.79); what we do is driven by what we know and we learn new things in order to do new things. Sutton's (2004) view is of knowledge as a necessary a priori for management action which, again, reflects a certain instrumental motivation behind management research; "the main reason managers should pay attention to scholarly research is that actions based on sound evidence trump those based on intuition" (p.27).

Against this background of differences in philosophy and purpose, management research methodologies are frequently portrayed as being irreconcilably oppositional. For example, Brannen (2005) suggests "the case for separate paradigms is that qualitative 
and quantitative researchers hold different epistemological assumptions, belong to different research cultures and have different research biographies that work against convergence" (p.173). Perhaps the most important element of this consideration of the approaches taken to research is their aptness for delivering either new or modified knowledge. In considering a Darwinian perspective, Dasgupta (2004) proposed that "the production of genuinely new knowledge - the products of creative thought-demands the generation of variations that are blind" (p.404). For Dasgupta, 'blind' has three characteristics; the process is independent of the arena in which it takes place, there is a selection process in place which tests new variations and there are mechanisms for retaining new and valuable variations. The question we would ask is, in this methodological conflict, is it the scientific quantitative approaches of the positivist philosophy which are winning out? Reed (2005) suggests that there is a growing emphasis on positivism in management research which is illustrated by ever wider adoption; "the intellectual roots of realism, as a philosophy of science and meta-theory ... has been diffused throughout the social and historical sciences and within organisation and management studies" (p.1629).

We would suggest that there are two factors which may explain any growth in positivist research. First, is the assumption of objectivity and independence; these methods allow the researcher to remain aloof from the phenomena under investigation, as Smith (2007) suggests "positive science is not conceived to be invalidated by its location in class struggle or social relations" (p.454). The second factor is that this independence has been learnt from other fields of study. For example, "applying scientific principles used in the medical sciences to management research will help in counteracting bias" (Tranfield et al, 2003, p.208). Issues surrounding this importation were raised by Ghoshal (2005) who argues that "over the last 50 years business school research has increasingly adopted the 'scientific' model ... based on partialisation of analysis, the exclusion of any role for human intentionality and the use of sharp assumptions and deductive reasoning" (p.76-77).

What, then, is the nature of knowledge created by these methodological debates? Cho and Matthews (1996) suggest that new knowledge is made up of two ingredients, explicit conceptual knowledge made up of "abstract representations which capture key variables" from quantitative research and "case based knowledge" from softer qualitative approaches (p.572). This mixing of methods is crucial because it can ferment debate and argument, a crucial catalyst in the knowledge production process according to Schreyogg and Geiger (2007); "arguments are the means by which inter-subjective recognition of a proponents hypothetically raised validity claim can be bought about and opinion thereby transformed into knowledge" (p.86). In recognising these issues of process, Jarzabkowski and Wilson (2006) sum up the research process thus; "theoretical knowledge goes through a process of dissociation which means it is rarely disseminated directly into practice ... Rather, theoretical knowledge is simplified into knowledge artefacts such as tools, techniques and frameworks" (p.349).

If the purposes of and approaches to management research combine to create output, Popper (1959) suggested that the output of academic research should primarily 
make a theoretical contribution to the field of study. He explained theory as "nets cast to catch what we call 'the world': to rationalise, to explain and to master it. We endeavour to make the net ever finer and finer" (p.59). If the output of research is primarily theoretical or, as Jarzabkowski and Wilson suggest, theoretically driven concepts, then it has a value for a number of reasons. Franklin (2004) suggested six reasons why theory is important: it helps to classify, clarify and define phenomena; it simplifies the world into variables in order to establish causes and effects; it offers predictions about the future; it aids and develops understanding of complex phenomena; it creates a common and universal language and means of communication; it reveals errors in the way the world is viewed. An interesting issue is how the value of theory is affected by the form of knowledge in which it is embedded.

Atherton (2003) supports the notion of academic research creating theoretical knowledge and suggests that this knowledge can be broadly characterised into two forms. On the one hand is positivist objectivised knowledge which is "rationalised, explicit and, hence, formal" (p.1389). This form of knowledge is decontextualised from the specifics of the analysis which generated it and is, in some way or other, generalisable. The second type of knowledge is subjectivised knowledge of a more phenomenological kind which has the characteristics of being "personal, implicit, subjective" (p.1390). This type of knowledge is specific to a context and, hence, not generalisable. Kreiner (2003) develops this point further and identifies useful and less useful knowledge. The less useful knowledge is that presented in 'pure' form in academic journals; "the type of knowledge our own research produces" which is "abstract and theorised" and it is not until it goes through Jarzabkowski and Wilson's artefact process that it becomes knowledge which "strikes people as more useful" (p.371). This division reflects Aram and Salipante's (2003) point that knowledge must combine elements of both rigour and relevance. Rigour is defined as "the academic person's commitment to build general theory ... theory constructed by rigorous methods which has a better chance of surviving challenges" and relevance is defined as "the framing of research questions and results which fit within the practicing manager's world and is presented in terms understandable to practitioners" (p.190).

The final element in this section of the paper is to draw together these ideas about purposes, approaches and outcomes to create a conceptual model through which we can analyse strategy research. This conceptual model is shown in Figure 1. There are a number of key points to make about the model. First, we have deliberately created a circular process. Our argument here is that knowledge is not a static phenomena but rather is subject to constant change over time as new circumstances arise and new theories are developed, tested, accepted and rejected. Second, research begins with some kind of creative act centred on theory, either in terms of something new or, perhaps more likely, in terms of adjustments to existing theoretical knowledge. 
Figure 1: $\quad$ A Process of Management Research

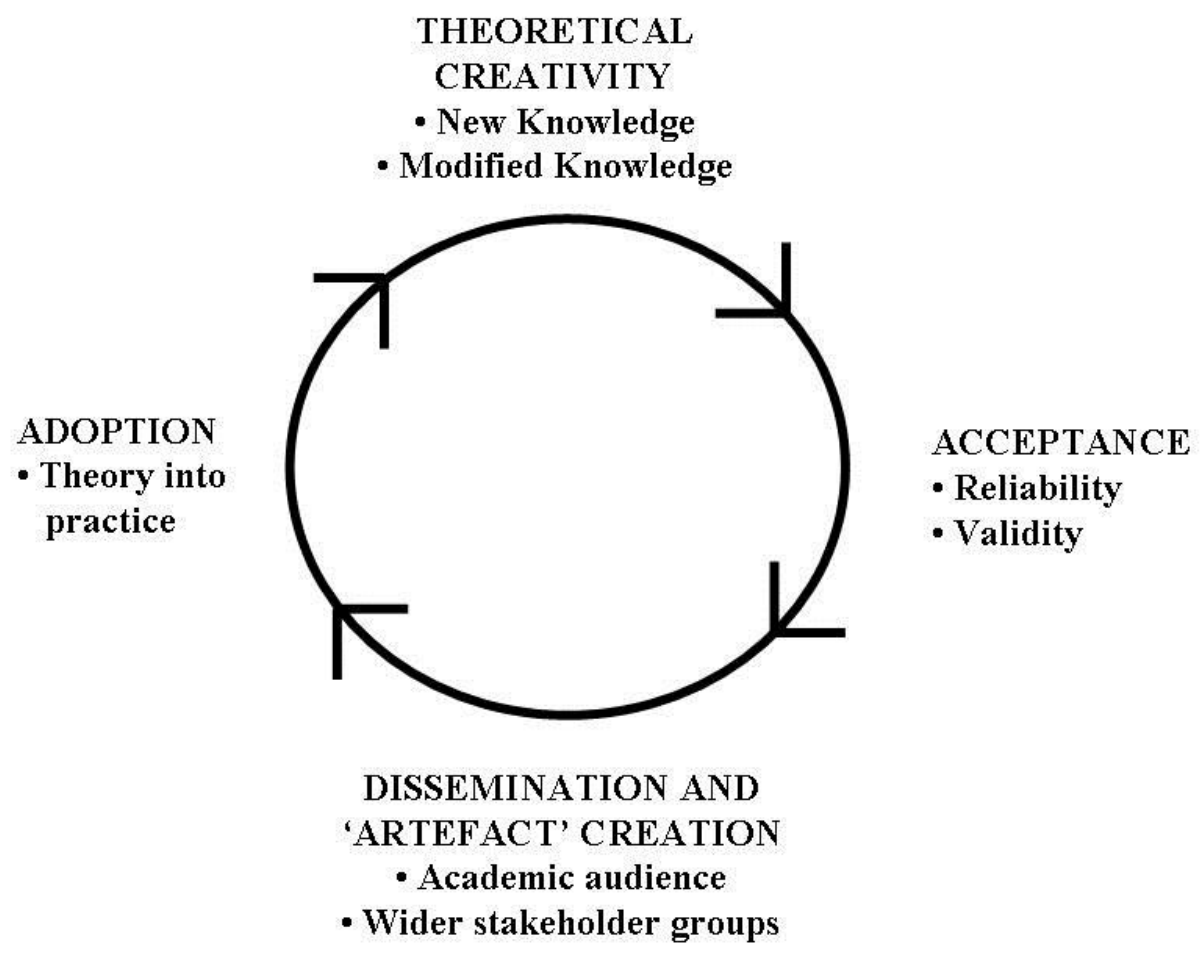

New ideas, in order to be accepted must go through a process through which their reliability and validity are established. Researchers can join this process at either the creative or acceptance points and we would characterise research which intervenes at the creative level as being an act of discovery and research which intervenes at the acceptance level as being an act of proof. Having established the worth of the knowledge created, we then suggest a process of dissemination occurs with the likelihood being that knowledge in its purest theoretical form is disseminated to an academic audience who instinctively understand the language and terminology and knowledge in the form of Jarzabkowski and Wilson's artefacts being disseminated to a non-academic audience. The final step in the process would be the adoption into practice of the theory developed by the research. We now move to discuss the underlying philosophies, processes and outcomes of strategy research between 2002 and 2006

The approaches to and contribution of strategy research: the numbers from the journals

Our discussion of the nature of strategy research focuses on two issues. First, what is the approach taken to research and, second, what is the outcome of research, especially in relation to the type of contribution to knowledge made. In discussing the approach taken to research, our concern is to identify the philosophical underpinning of that research and, in particular, whether the research comes from a positivist perspective. Doolin (1996), for example, suggests that understanding any piece of academic research 
must necessarily begin with a discussion of its philosophical a priori as this determines the key elements of that research. This is supported by Hudson and Ozanne (1988) who suggest that all research is, at the least, influenced by a set of assumptions about the "the nature of reality, of social being and of what constitutes knowledge" (p. 508). In determining whether or not research is positivist we would suggest that positivist research will have its own set of ontological, epistemological and methodological characteristics which will form the basis of our own classifications.

Ontologically, positivism begins with the notion that the nature of being can be understood in an external and objective manner; it is possible for an observer to understand the true nature of any particular phenomenon because not only is he or she independent of it but also because that phenomenon has a truth to it which is "independent of what individuals perceive" (Hudson and Ozanne, 1988, p. 509). Chen and Hirschheim (2004) suggest that this means "reality exists objectively" (p. 201) and so, according to Straub et al. (2004) it is always possible to generate a "relatively accurate representation of the underlying phenomenon" being explored (p. 7). This point is further supported by Doolin (1996) who argues that this is possible because of the "passive, neutral" role of the researcher (p. 22).

These ontological assumptions naturally give rise to a specific positivist epistemology which privileges two elements. First, the understanding of phenomena as a set of "significant facts" (Lee, 1999, p. 30) and, second, generalisability of research so that one understands what can be "expected in the circumstances" (Dessler, 1999, p. 128). What is known through positivist research is, therefore, assumed to have a degree of accuracy, especially in relation to research questions (Hudson and Ozanne, 1988, p. 512) and rests on the assumption that, amongst other phenomena, "nature is objectively verifiable" (Straub et al., 2004, p. 6). The aim, therefore, of positivist research is to explain events and, in doing so, provide a set of fundamental laws about behaviour, what Cooper (1997) describes as "certainty and universally generalisable results" (p. 558).

Whilst there may be reasonably clear ontological and epistemological characteristics of positivist research, methodologically there is some diversity. Cooper (1997) suggests that this type of research is carried out in such a way that it "links objectivity with empirical and quantitative methods" (p. 557) and the result of this is a tendency towards the formulation and testing of hypotheses (for example, Chen and Hirschheim, 2004) whose aim is to match "facts with theory" (Lee, 1999, p. 30). This is frequently done through research approaches involving quantitative methods, surveys and experiments (Doolin, 1996, p.22).

In defining positivist research Chen and Hirschheim (2004) suggest that it can be identified by the presence or absence of three things; hypotheses, quantitative methods and inferences made from sample to general population. Hudson and Ozanne (1988) offer a similar approach and suggest positivist research will always involve four steps: the establishment of a clear theoretical base to the research; the development of strict research protocols; the ensuring of validity and reliability; the discussion of the statistical 
significance of any findings. In synthesising these discussions of positivist research, Table 1 defines the characteristics of positivist research used in this study.

Table 1: $\quad$ Characteristics of Positivist Research

\begin{tabular}{|l|l|l|}
\hline Assumption & $\begin{array}{l}\text { The research assumes that the observer is } \\
\text { independent of that being observed which is, itself, } \\
\text { external and objective }\end{array}$ & $\begin{array}{l}\text { Chen } \\
\text { Hirschheim (2004) } \\
\text { Hudson and Ozanne } \\
(1988) \\
\text { Straub et al. (2004) }\end{array}$ \\
\hline Objective & $\begin{array}{l}\text { The research focuses on the discovery of facts and } \\
\text { the generation and/or testing of fundamental laws } \\
\text { Hudson and Ozanne } \\
(1988) \\
\text { Straub et al. (2004) } \\
\text { Lee (1999) } \\
\text { Dessler (1999) } \\
\text { Doolin (1996) } \\
\text { Cooper (1997) }\end{array}$ \\
\hline Method & $\begin{array}{l}\text { The approach to research often involves the testing } \\
\text { of formulated hypotheses through the frequent use } \\
\text { of large scale and quantitative methods }\end{array}$ & $\begin{array}{l}\text { Chen } \\
\text { Hirschheim (2004) } \\
\text { Lee (1999) } \\
\text { Doolin (1996) } \\
\text { Cooper (1997) } \\
\text { Straub et al. (2004) }\end{array}$ \\
\hline
\end{tabular}

We now turn to discuss how we categorise the contributions to knowledge made by the articles in our sample. Just as identifying the philosophical underpinnings of research is a complex activity, so too is defining the outcome of any piece of academic research. In most articles, methodologies are clearly explained and rationalised but this is frequently not the case with contributions to knowledge which are, for example, often determined by the value judgements of the reader as much as they are by the aims and objectives of the author. In evaluating articles in this area, we have developed four classifications: Developing Theory; Stretching Theory; Reflections; Other.

In discussing whether or not an article makes a significant contribution to the development of theory, our starting point is Dasgupta's (2004) point that the creation of new theory is necessarily a "creative process" (p. 405). This notion is reinforced by Vermunt (2005) who suggested that contributions to theory can be viewed as "new ways of seeing" (p. 330) and this is likely to be driven by a quest for "discovery" as much as it as a quest for proof (p. 229). Collins (1993) characterises new theory as having "influencing ambitions" (p. 98) which implies that the purpose of this kind of research is much more about opening up new avenues for others to investigate than it is about travelling down avenues opened elsewhere. New theory, therefore, must involve "exploration beyond the limits of foresight" (Dasgupta, 2004, p. 404) which suggests that the establishment of existing theory can, more often than not, inhibit the development of new theory through a creative process. 
In classifying articles as making a contribution which stretches theory, we are mainly considering articles whose contribution is contextual rather than theoretical. These are articles whose main purpose and contribution has been to further test the generalisability of existing theory. Cordell et al. (2006), for example, discuss these types of article in relation to the "implications that have relevance to the real world inhabited by practitioners" (p. 78) and this is reinforced by Schreyogg and Geiger (2007) who discuss academic research as taking theory through a variety of different contexts in order to continually test and establish its "validity claim" (p. 83). Research in this area will frequently not extend our understanding of theory, per se, but will be much more successful in extending our understanding of where theory can and cannot be applied. Sutton (2004) sees this as not just a role for academics but also for practitioners to take theory and apply it which develops further Baldridge at al's (2004) view that much academic research is about understanding "theories in use" (p. 1073) rather than it is about developing new theories for use.

Our third classification, 'Reflections', are for those articles which are explicitly about the field of strategy and how it is studied, represented in the literature and types of paper being produced (Phelan et al., 2002). These articles will review theory rather than critically engage with it and will take a number of forms such as epistemologies, typologies and philosophies. The aims of these articles will vary depending on author and journal but include, for example, "an understanding of the field's intellectual foundations" (Powell, 2002, p. 874), the identification of "the works that have had the greatest impact" (Ramos-Rodriguez and Ruiz-Navarro, 2004, p. 982) and to ensure that strategy "can be studied more rigourously" (Bergh and Fairbank, 2002, p. 360). Our final classification, 'Other', is for articles which do not readily fit any of the other categories and is made up primarily of articles which make no real theoretical contribution to knowledge and contain, for example, case studies or business leader profiles.

Having established the criteria on which strategy research is to be evaluated, we now turn to discuss sample selection and the evaluation process itself. The sample used to collect data for this article is drawn from two well known and widely used journal quality guides. First, is the Harvey et al. (2007) guide published by the Association of Business Schools (ABS) and, second, is the Harzig (2005) guide published by the University of Melbourne, currently in its $14^{\text {th }}$ edition, which acts as a summary of 14 different guides to the quality of academic publications. All of the journals are designated in the guides as either being specialist 'Strategy' journals or 'General Management and Strategy' journals. In evaluating articles from this sample of journals there are three main problems. The first problem is the diversity of article types; across the 23 journals there are different types of article such as research articles, viewpoints, book reviews and editorials. As the purpose of this research is to assess the underlying philosophy and contribution made by strategy research it was decided that non-research articles would be excluded; it is unlikely that, for example, book reviews and editorials would have a clearly defined methodology or look to make any sort of contribution to knowledge in the sense discussed above. 
The second problem is that of which articles from these journals can be classified as strategy articles and, therefore, should be included in the study. Whilst this may seem less of a problem for articles in specialist strategy journals, there is still scope for debate as to the precise and exact meaning of strategy; Chaharbaghi and Willis (1998), for example, in reviewing the strategy literature found over 50 different and competing definitions of strategy in common usage. The problems were most manifest, however, in journals which had been described as 'General Management and Strategy'. For example, the period under discussion saw a significant growth in articles published in areas such as 'strategic human resource management', strategic marketing' and so on and there is uncertainty as to whether these are, for instance, HRM articles discussed in a strategy context or strategy articles examined through the prism of HRM. To overcome these problems, articles from general management journals had to meet one of three criteria: Either the title of the article had to have an explicit reference to strategy or the abstract had to place the article in the field of strategy or the key words listed for the article had to include strategy or derivatives thereof. On the basis of these selection criteria, we have a sample of almost 4,000 articles.

The final problem generated by this sample was not one of selection criteria but rather one of evaluation criteria, in particular how to evaluate research articles which adopted a mixed method approach to their studies. Mixed methods offer an approach to management research which is growing in prevalence and popularity (see, for example, Johnson and Onwuegbuzie (2004), Hanson et al. (2005), Teddlie and Yu (2007), Collins et al. (2007)) and does raise some issues for the evaluation of individual articles. Yin (2006), for example, discusses the extent to which studies using mixed methods offer "integrated or parallel" (p. 41) approaches and this can be a crucial test of the rigour of any methodology. In this study, however, we would argue that this is less of a problem for two main reasons. First, whilst the methodological approach to research is a crucial indicator of the underlying philosophy of that research it is just one of a number of indicators; this study is not assessing methodology in and of itself but rather is assessing the philosophical a priori of methodology. Second, whilst positivist philosophies do tend towards certain methodological preferences, they do not preclude all other methodological preferences and so it is possible to be both positivist and mixed method.

One of the key elements of this study is the examination of differences across journal articles on the basis of their quality. For the sake of consistency, the quality rankings for individual journals have all been taken from the ABS guide which ranks journals from a low of $0^{*}$ to a high of $4^{*}$. Given that journals ranked at $0^{*}$ are commonly perceived as making no real contribution to knowledge, journals at this level have been ignored and only journals ranked between $1^{*}$ and $4^{*}$ have been included. The sample, therefore, contains articles from 23 journals with six each ranked at $1^{*}, 2^{*}$ and $3^{*}$ and five ranked at $4^{*}$. Similarly, consistency is also demanded in the evaluation of philosophy and contribution to knowledge; whilst this article has been co-authored, in order to main consistency across the sample just one of the authors was responsible for the evaluation of articles. Table 2 below shows the characteristics of the sample under discussion. 
Table 2: $\quad$ Sample Characteristics

\begin{tabular}{|c|c|c|c|}
\hline Ranking & Journal name & $\begin{array}{c}\text { Number of } \\
\text { articles } \\
\text { reviewed }\end{array}$ & Total \\
\hline \multirow[t]{5}{*}{$4 *$} & Industrial and Corporate Change & 198 & \multirow[b]{5}{*}{1286} \\
\hline & Journal of Business & 288 & \\
\hline & Journal of Management & 204 & \\
\hline & Journal of Management Studies & 296 & \\
\hline & Strategic Management Journal & 300 & \\
\hline \multirow[t]{7}{*}{$3 *$} & British Journal of Management & 128 & \multirow[b]{7}{*}{832} \\
\hline & $\begin{array}{l}\text { Journal of Economics and Management } \\
\text { Strategy }\end{array}$ & 145 & \\
\hline & Journal of Management Inquiry & 113 & \\
\hline & Journal of World Business (Columbia) & 140 & \\
\hline & Long Range Planning & 127 & \\
\hline & Management International Review & 179 & \\
\hline & & & \\
\hline \multirow[t]{7}{*}{$2 *$} & Advances in Strategic Management & 71 & \multirow[b]{7}{*}{806} \\
\hline & Business Strategy and the Environment & 131 & \\
\hline & International Business Review & 180 & \\
\hline & Journal of International Management & 115 & \\
\hline & Strategic Change & 170 & \\
\hline & $\begin{array}{l}\text { Technology Analysis and Strategic } \\
\text { Management }\end{array}$ & 139 & \\
\hline & & & \\
\hline \multirow[t]{6}{*}{$1 *$} & Business Strategy Review & 208 & \multirow[b]{6}{*}{983} \\
\hline & Foresight & 184 & \\
\hline & Handbook of Business Strategy & 159 & \\
\hline & Journal of Business Strategy & 187 & \\
\hline & Strategic Organisation & 68 & \\
\hline & Strategy and Leadership & 177 & \\
\hline
\end{tabular}

We now turn to consider the results of our analysis and we begin with the approaches taken to research. The results for the sample as a whole, broken down by journal ranking, are presented in Table 3. Across the sample there is a clear tendency towards positivist approaches to research and so it is likely that strategy is more often than not investigated using some kind of quantitative approach. However, whilst positivistic philosophies are more prevalent, they do not dominate the sample as just 55\% of strategy research is positivist. This picture changes significantly, however, when we consider approaches to research on the basis of journal rankings. In the lowest ranked journals, just one in five articles is positivist in character compared to four in five in the 
$4^{*}$ journals. Across the middle ranked journals there is little to choose with $2^{*}$ and $3^{*}$ journals having similar levels of positivist content.

Table 3: $\quad$ Approaches to Strategy Research

\begin{tabular}{|c|c|c|c|}
\hline $\begin{array}{c}\text { Journal } \\
\text { Ranking }\end{array}$ & Positivist Approach & $\begin{array}{c}\text { Non-Positivist } \\
\text { Approach }\end{array}$ & Total \\
\hline \multirow{2}{*}{$4^{*}$} & 1003 & 283 & $\mathbf{1 2 8 6}$ \\
\cline { 2 - 4 } & $78.0 \%$ & $22.0 \%$ & $\mathbf{8 3 2}$ \\
\hline \multirow{2}{*}{$3^{*}$} & 505 & 327 & $\mathbf{8 0 6}$ \\
\hline \multirow{2}{*}{$2^{*}$} & $60.7 \%$ & $39.3 \%$ & $\mathbf{9 8 3}$ \\
\cline { 2 - 4 } & 454 & 352 & \\
\hline \multirow{2}{*}{$1^{*}$} & $53.3 \%$ & $43.7 \%$ & $\mathbf{3 9 0 7}$ \\
\hline Total Articles & 208 & $78.8 \%$ & \\
\cline { 2 - 4 } & $21.2 \%$ & $\mathbf{1 7 3 7}$ & $\mathbf{4 4 . 5 \%}$ \\
\hline
\end{tabular}

There are also significant variations across individual journals. For example, in the five year period under consideration the Journal of Business published just one article that was not explicitly positivist and in the leading specialist strategy journal, the Strategic Management Journal, practically $90 \%$ of all articles were positivist. Again this is in contrast to the lower tiers; the Handbook of Business Strategy had just 10\% of its published articles from this perspective and the most positivist of the $1^{*}$ journals, Strategic Organisation, had just $40 \%$ of its articles in this area. Mid ranking journals like the British Journal of Management and Long Range Planning had a roughly equal mix of positivist and non-positivist articles in contrast to similarly ranked journals like the Journal of Economics and Management Strategy in which $90 \%$ of its articles were positivist.

Table 4: $\quad$ Approaches Taken to Strategy Research of Selected Journals (number of articles published)

\begin{tabular}{|l|c|c|}
\hline Journal Title & $\begin{array}{c}\text { Postitivist } \\
\text { Approach }\end{array}$ & $\begin{array}{c}\text { Non-Positivist } \\
\text { Approach }\end{array}$ \\
\hline British Journal of Management & 64 & 64 \\
\hline Handbook of Business Strategy & 17 & 142 \\
\hline Journal of Business & 287 & 1 \\
\hline $\begin{array}{l}\text { Journal of Economics and Management } \\
\text { Strategy }\end{array}$ & 131 & 14 \\
\hline Long Range Planning & 64 & 63 \\
\hline Strategic Management Journal & 261 & 39 \\
\hline Strategic Organisation & 29 & 39 \\
\hline
\end{tabular}

Our general conclusions about research methodology in the field of strategy is that, for researchers, publishing in the top ranked journals may require quantitative 
research from a positivist perspective: All the $4 *$ journals, five out of six $3 *$ journals and two thirds of $2^{*}$ journals are dominated by positivist research. This may suggest a number of things. First, it suggests that these approaches to research are, at least perceived, as being more rigorous than non-positivist research. Second, it suggests that researchers with a non-positivist view of the world could find it harder to publish in the top ranked journals. Finally, it raises the interesting question of why this may all be so; why does much strategy research seem to be dominated by positivist philosophies?

In light of these results about approaches taken, we now present the results of our analysis as to the contribution made by strategy research. The results are presented in Table 5 in a similar format to that already presented.

Table 5: $\quad$ The Contribution of Strategy Research

\begin{tabular}{|c|c|c|c|c|c|}
\hline $\begin{array}{c}\text { Journal } \\
\text { Ranking }\end{array}$ & $\begin{array}{c}\text { Developing } \\
\text { Theory }\end{array}$ & $\begin{array}{c}\text { Stretching } \\
\text { Theory }\end{array}$ & Reflections & Other & Total \\
\hline \multirow[t]{2}{*}{$4 *$} & 196 & 941 & 49 & 100 & 1286 \\
\hline & $15.2 \%$ & $73.2 \%$ & $3.8 \%$ & $7.8 \%$ & \\
\hline \multirow[t]{2}{*}{$3 *$} & 97 & 642 & 33 & 60 & 832 \\
\hline & $11.7 \%$ & $77.2 \%$ & $4.0 \%$ & $7.2 \%$ & \\
\hline \multirow[t]{2}{*}{$2 *$} & 72 & 569 & 12 & 153 & 806 \\
\hline & $8.9 \%$ & $70.6 \%$ & $1.5 \%$ & $19.0 \%$ & \\
\hline \multirow[t]{2}{*}{$1 *$} & 9 & 608 & 4 & 362 & 983 \\
\hline & $0.9 \%$ & $61.9 \%$ & $0.4 \%$ & $36.8 \%$ & \\
\hline \multirow{2}{*}{$\begin{array}{c}\text { Total } \\
\text { Articles }\end{array}$} & 374 & 2760 & 98 & 675 & 3907 \\
\hline & $9.6 \%$ & $70.6 \%$ & $2.5 \%$ & $17.3 \%$ & \\
\hline
\end{tabular}

The first interesting point is that only a small amount of strategy research makes a significant theoretical contribution to knowledge; less than one in every ten articles published either develops a new theory or makes a significant modification to an existing one. Practically no research at the bottom end of the sample takes this form; just nine articles out of almost 1,000 were of this nature. Most theoretical contributions come from the top tier of journals as more than half of all the advances in strategy theory in this sample came from the five $4^{*}$ ranked journals. However, even amongst these journals, theoretical innovation is the exception rather than the rule and it accounts for just $15 \%$ of published output. The highly specialised Strategic Management Journal makes the most theoretical advances and this journal accounts for almost one-third of the total across the sample. Of the middle ranking journals, those with the largest mix of approaches to research (the British Journal of Management and Long Range Planning) make the most theoretical advances and, among the $4 *$ journals, the most positivist (Journal of Business) makes the least advances.

Across all the tiers of journals, most research is about stretching knowledge into new contexts and this takes different forms across different journals. For example, at the top end of the sample, the evidence on processes of research suggests that most research is about further proving generalisability of theory through the use of quantitative 
methods. At the lower end of sample, however, most research stretches existing theory into much more specific contexts. Interestingly, it is in the $3^{*}$ journals that the most stretching of theory takes place and amongst these journals the one with the lowest levels of advancing theoretical knowledge, Management International Review, has the highest levels of theory stretch.

Across the field of strategy, as reflected in this sample, just one article in every 40 reflects on the field of strategy. The key trend here is that if there is little reflection taking place at the upper end of the sample, there is practically none at all at the bottom. The Strategic Management Journal is the most reflective of all the journals and accounts for $20 \%$ of the reflective articles across the whole sample. The Journal of Business is the least reflective journal of all the $4^{*}$ ranked publications and, of the 23 journals reviewed, nine did not contain a single article reflecting on the study of strategy.

Table 6: $\quad$ The Contribution to Strategy Research of Selected Journals (number of articles)

\begin{tabular}{|l|c|c|c|c|}
\hline Journal Title & $\begin{array}{l}\text { Developing } \\
\text { Theory }\end{array}$ & $\begin{array}{l}\text { Stretching } \\
\text { Theory }\end{array}$ & Reflections & Other \\
\hline $\begin{array}{l}\text { British Journal of } \\
\text { Management }\end{array}$ & 20 & 94 & 9 & 5 \\
\hline Journal of Business & 11 & 250 & 0 & 26 \\
\hline $\begin{array}{l}\text { Long Range } \\
\text { Planning }\end{array}$ & 21 & 96 & 6 & 12 \\
\hline $\begin{array}{l}\text { Management } \\
\text { International Review }\end{array}$ & 10 & 151 & 20 & 14 \\
\hline $\begin{array}{l}\text { Strategic } \\
\text { Management Journal }\end{array}$ & 60 & 206 & & \\
\hline
\end{tabular}

Across the sample, almost one in five articles published in the field of strategy makes no real contribution to theoretical knowledge at all. This is a much more significant phenomena at the lower end of the sample where one-third of all articles are non-theoretical and, by implication, non-academic. It is less of an issue in the highest ranked journals where just under $8 \%$ of articles are of this character. Of these journals, the Journal of Business has the most articles of a non-theoretical nature and so, given that its content is almost exclusively positivist, in a pure academic sense these articles may be little more than exercises in mathematics.

\section{Discussion and implications}

Paul Krugman suggested that, in economics and evolutionary biology, the key to getting your work published in top ranked journals is to "make a conceptually minor but mathematically difficult extension to some familiar model". He suggests that economists and evolutionary biologists must demonstrate a mastery of complex statistical methods much more than knowledge of the mechanics of a marketplace or post-Darwinian adaptation. The dilemma, therefore, is between research which is driven by process and 
research which is driven by the subject itself. It is reasonable to ask what it is that strategy researchers are demonstrating: an understanding of strategy or an understanding of positivist and quantitative approaches to research? In many cases it is both but in others it is the latter which is no absolute guarantee of the former.

This research raises a basic question, therefore, about the study of strategy: Can the eclectic, diverse, dynamic and ever changing nature of strategy in practice be accurately reflected in research whose philosophical underpinnings are likely to create a very narrow methodological base? Within this discussion, this study does not reflect on how this has come about. Is the philosophical content of strategy journals, especially in highly ranked strategy journals, a product of editorial policy or is it the result of the preferences of submitting authors? Whichever way that question is answered will raise substantial issues about academic prestige and reputation, career progression and intellectual integrity which are well beyond the scope of this study. What is not, however, beyond the scope of the study, is a discussion of some of the implications of this philosophical dominance.

In discussing the implications of this, we note that few of these issues are new but they do serve to reinforce points made earlier about the field of strategy research specifically and management research in general. Tranfield et al (2003), for example, argue that strategy research offers bad service to both theory and practice; "there is a considerable and widening divide between academics and other stakeholder groups and this divergence is likely to further proliferate irrelevant theory and untheorised and invalid practice" (p.211). This problem manifests itself in two ways. First is the growing disconnect between the theory and practice of strategic management. For example, Jarzabkowski and Wilson (2006) argue "the paradox is that, despite its plural and diverse approaches, the relevance of strategy knowledge to practice is increasingly questioned" (p.348) and this point is reinforced by Cordell et al (2006) who argue "many practitioners feel that academics don't appreciate the complexities of the practitioner's world, and many feel that academic research is too theoretical to have relevance to them" (p.72). The second manifestation is in the breakdown in the communication of strategy knowledge around which there are a number of complementary perspectives. For example, Barrett and Barrett (2003) suggest that the problem is in the arcane language of the academic world which few outside are willing or able to engage with; "academic research has long been accused by practitioners of having a low level of applicability ... research is heavy stuff, after the first page we fall asleep" (p.755). In a slightly different way, Brannen (2005) complains about the need for academics to have multi-faceted communication skills; "researchers today are required to communicate in 'double speak': in the specialised languages that define their field and in a generic, popular language that addresses research users" (p.175). All of this demands a number of modifications to the conceptual model developed earlier and these are presented in Figure 2 . 
Figure 2: $\quad$ A Revised Process of Management Research

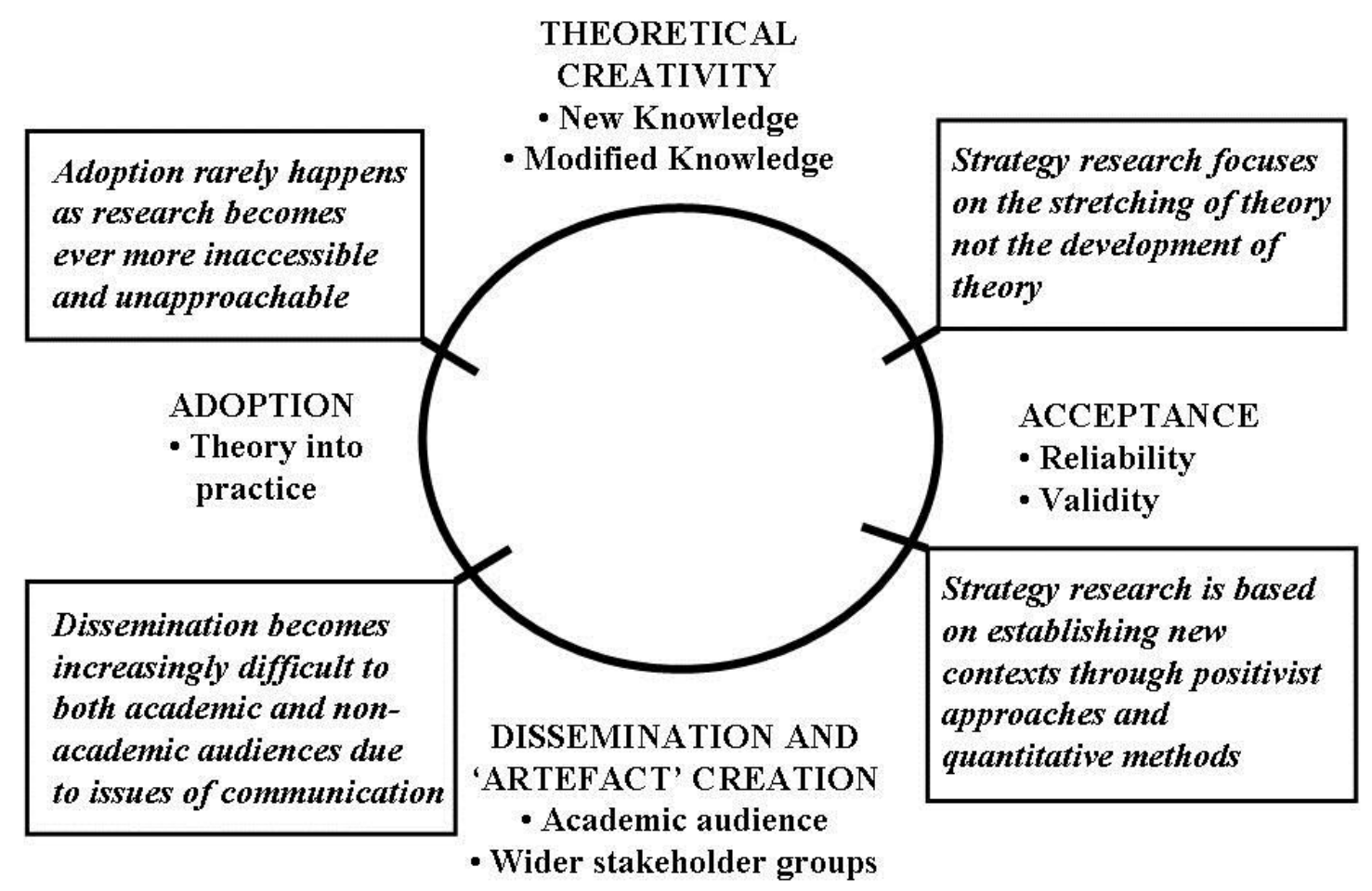

If strategy research has become more process driven, then this weakness in the way in which strategy is studied seems not to be recognised and this is possibly because of the lack of reflection on the study of strategy. The evidence from the previous section suggested a problem of quantity and further evidence suggests that there is also a problem of content: Reflection does not happen very often and, when it does, it is done in a very narrow way. Within the limited body of reflective work in the field of strategy research there are two broad problems. First, reflections tend to be insular in both tone and content. Second, where they generate debate, it is rarely about the central theories or concepts of strategy.

In order to illustrate these points, we will use examples from the Strategic Management Journal, the most reflective of all the journals in the sample. For example, Boyd et al (2005) discuss how strategy has changed in the 25 years since its inception as a field of study and immediately note that this coincides with "the Silver Anniversary of the Strategic Management Journal" (p.841) before discussing the changing nature of strategy as solely represented by articles from the Strategic Management Journal. Similarly, Ramos-Rodriguez and Ruiz-Navarro (2004) discuss the "intellectual structure of strategic management research" (p.982) with reference to articles only from the Strategic Management Journal and Podsakoff et al (2005) discuss the influence of management journals (primarily on other management journals) and nearly two-thirds of their citations are from the Strategic Management Journal. 
This lack of interaction with other journals may create insularity in the field and the result is that issues of theoretical controversy are replaced by issues of process controversy. Between 2002 and 2006 the study found very few papers which reflected on strategy as theory or strategy as practice but there were many which reflected on how strategy is examined by academics. For example, Boyd et al (2005) deal with construct measures, Rouse and Daellenbach (2002) deal with new research methods to investigate the resource based view of strategy and Ray et al (2004) discussed how dependent variables could be chosen when investigating the resource based view of strategy. All used a positivist methodology in doing so. A final implication of this could be that the debate in strategy is not based on the best ideas but rather on different ways of generating numbers.

The characteristics of strategy research identified in this paper, and the weaknesses inherent in them, are caused, according to Sutton (2004), by a number of different factors. First is the experience gap; academics are not, in the main, equipped to talk about managers because they have never been managers. This would seem to be a criticism peculiar to the management researcher. Historians, for example, are rarely criticised because they do not live in the $16^{\text {th }}$ century or astronomers because they have never been in space. Notwithstanding this point, Sutton does make a number of relevant interventions, however, such as that of the use of academic jargon ("so much of it is incomprehensible to anyone but a fellow overtrained academic" (p.28)), academic debate (which focuses on issues that "are of no practical value to anyone" (p.29)) and the slow pace of academia compared to the world of business. The evidence presented in this study suggests that there is merit in Sutton's arguments.

\section{Conclusions}

Before identifying the main lessons from our analysis and suggestions for future research, we would first place them into context by discussing the main limitations of this study. The aim of this paper was to take a snapshot of strategy research and assess it on the basis of its philosophical underpinning and contribution to knowledge and, therefore, the first weakness is that it lacks any real comparative content. This limitation takes two forms. First, we have undertaken no time based comparisons and so can offer little by way of discussion as to whether the philosophical underpinnings and contributions to knowledge have changed over time. Despite analysing almost 4,000 articles we are not in a position to discuss whether strategy research is more or less diverse, eclectic, creative or reflective than it used to be. The second form of this limitation is disciplinary as we have not compared strategy research to other management disciplines like HRM, marketing, operations and so on. Thus, again, we offer no insights into whether the characteristics of strategy research are reflected in management research in other areas. We would justify this lack of comparative date in two ways. First, our intention was never to make such comparisons and, in an article of this length, it would be impossible to them justice. Second, it opens up a whole series of other avenues of investigation for both ourselves and other like minded (and non-like minded) social scientists. 
The other major limitation of this study is that, whilst it offers much on the characteristics of strategy research, it offers much less in terms of explaining cause and effect. The literature on strategy is dominated by positivist research and the most telling contribution that most of it makes is to stretch theory into previously unexplored contexts but the relationship between the two is unclear and open to debate. For example, is it the nature of positivist research that makes the stretching of theory most likely? As positivist research has a tendency towards the statistical testing of theory derived hypotheses, it may be inevitable that much of it is just a test of further generalisability of established wisdom. Alternatively, is it all about aims and objectives? If the objective of much strategy research is to test further generalisability of established wisdom then positivist approaches will dominate as they offer the most appropriate methodologies to meet such an ambition. Again we would justify this weakness with the limited scope of the article and its purposes and point out the rich vein of possibilities that it opens up for other researchers.

Munslow (2001) defines history as a narrative in which events and happenings are illustrations of something less tangible but more important: the battle of ideas. Progress happens as a product of competition between theories, ideologies and philosophies and in the social scientific world, as in the animal kingdom, things do not progress and innovations do not happen without that competition. The evidence we have presented suggests that strategy research may have reached what Fukuyama described as the "end of history" when philosophical debates seem to have been won and the intellectual world relaxes back into its tried, tested and comfortable ways. The result of this may well be that strategy research increasingly becomes a quest to prove what we already know to be right and too infrequently becomes a voyage of discovery. As strategy as a subject for academic investigation settles onto its positivist foundations, we present our final implication as a question: Where is the competition in strategy research that may deliver the next big idea?

\section{References}

Advances in Strategic Management volumes 19-23.

Aram, J.D. and Salipante, P.F. Bridging Scholarship in Management: Epistemological Reflections. British Journal of Management, 2003, 14, 189-205.

Atherton, A. The uncertainty of knowing: An analysis of the nature of knowledge in a small business context. Human Relations, 2003, 56, 1379-1398.

Ayer, A. The Foundations of Empirical Knowledge. London, Macmillan, 1968.

Baldridge, D.C., Floyd, S.W. and Markocz, L. Are Managers from Mars and Academicians from Venus? Toward an understanding of the relationship between academic quality and practical relevance. Strategic Management Journal, 2004, 25, 1063-1074.

Barrett, P.S. and Barrett, L.C. Research as a kaleidoscope on practice. Construction Management and Economics, 2003, 21, 755-766.

Bergh, D.D. and Fairbank, J.F. Measuring and Testing Change in Strategic Management Research. Strategic Management Journal, 2002, 23, 359-366. 
Bergh, D.D., Perry, J. and Hanke, R. Some Predictors of SMJ Article Impact. Strategic Management Journal, 2006, 27, 81-100.

Bishop, M.A. and Trout, J.D. Epistemology's search for significance. Journal of Experimental Theory and Artificial Intelligence, 2003, 15, 203-216.

Blackler, F. Knowledge, Knowledge Work and Organisations: An overview and interpretation. Organization Studies, 1995, 16, 1021-1046.

Boyd, B.K., Gove, S. and Hitt, M.A. Construct Measurement in Strategic Management. Strategic Management Journal, 2005, 26, 239-257.

Boyd, B.K., Finkelstein, S. and Gove, S. How Advanced is the Strategy Paradigm? The role of particularism and universalism in shaping strategy outcomes. Strategic Management Journal, 2005, 26, 841-854.

Brannen, J. Mixing Methods: The entry of qualitative and quantitative approaches into the research process. International Journal of Social Research Methodology, 2005, 8, 173-184.

British Journal of Management volumes 13-17.

Business Strategy and the Environment volumes 11-15.

Business Strategy Review volumes 13-17.

Chaharbaghi, K. and Willis, R. Strategy: The missing link between continuous revolution and constant evolution. International Journal of Operations and Production Management, 1998, 18, 1017-1027.

Chen, W. and Hirschheim, R. A paradigmatic and methodological examination of information systems research from 19991 to 2001. Information Systems Journal, 2004, 14, 197-235.

Cho, J-R. and Matthews, R.C. Interactions between mental models used in categorization and experiential knowledge of specific cases. The Quarterly Journal of Experimental Psychology, 1996, 49, 572-595.

Collins, H.M. The Structure of Knowledge. Social Research, 1993, 60, 95-116.

Collins, K., Onwuegbuzie, A. and Jiao, Q. A Mixed Methods Investigation of Mixed Methods Sampling Designs in Social and Health Science Research. Journal of Mixed Methods, 2007, 1, 267-294.

Cooper, M. On objectivity in qualitative research. College Composition and Communication, 1997, 48, 556-561.

Cordell, D.M., Langdon, T.P. and Lemoine, C.W. Bridging the Gap: Academic research that is relevant to practitioners. Journal of Financial Service Professionals, 2006, November, 72-78.

Dasgupta, S. Is Creativity a Darwinian Process? Creativity Research Journal, 2004, 16, 403-413.

Dessler, D. Constructivism within a positivist social science. Review of International Studies, 1999, 25, 123-137.

Doolin, B. Alternative views of case research in information systems. Australasian Journal of Information Systems, 1996, 3, 21-29.

Fawcett, B. and Hearn, J. Researching Others: Epistemology, experience, standpoints and participation. International Journal of Social Research Methodology, 2004, 7, 201-218.

Foresight volumes 4-8. 
Franklin, P. Problematics in management theory and practice. Strategic Change, 2004, 13, 383-404.

Ghoshal, S. Bad management theories are destroying good management practices. Academy of Management Learning and Education, 2005, 4, 75-91.

Hakala, J. and Ylijoki, O. Research for Whom? Research orientations in three academic cultures. Organization, 2001, 8, 373-380.

Handbook of Business Strategy volumes 3-7

Hanson, W., Creswell, J., Plano Clark, V., Petska, K. and Creswell, J. Mixed Methods Research Designs in Counseling Psychology. Journal of Counseling Psychology, 2005, 52, 224-235.

Harvey, C., Morris, H. and Kelly, A. Academic Journal Quality Guide. London, Association of Business Schools, 2007.

Harzig, A-W. Journal Quality List. Melbourne, University of Melbourne, 2005.

Hassell, L. A continental philosophy perspective on knowledge management. Information Systems Journal, 2007, 17, 185-195.

Hermann, P. Evolution of Strategic Management: The need for new dominant designs. International Journal of Management Reviews, 2005, 7, 111-130.

Hudson, L. and Ozanne, J. Alternative ways of seeking knowledge in consumer research. Journal of Consumer Research, 1988, 14, 508-521.

Industrial and Corporate Change volumes 11-15.

International Business Review volumes 11-15.

Jarzabkowski, P. and Wilson, D.C. Actionable Strategy Knowledge: A practice perspective. European Management Journal, 2006, 24, 348-367.

Johnson, R. and Onwuegbuzie, A. Mixed Methods Research: A research paradigm whose time has come. Educational Researcher, 2004, 33, 14-26

Journal of Business volumes 75-79.

Journal of Business Strategy volumes 24-27.

Journal of Economics and Management Strategy volumes 11-15.

Journal of International Management volumes 8-12.

Journal of Management volumes 28-32.

Journal of Management Inquiry volumes 11-15.

Journal of Management Studies volumes 39-43.

Journal of World Business (Columbia) volumes 37-41.

Kreiner, K. Forbidden Knowledge - or merely hidden? Management Learning, 2003, 34, 371-373.

Lavis, J.N., Robertson, D., Woodside, J.M., McLeod, C.B. and Abelson, J. How can research organisations more effectively transfer research knowledge to decision makers? The Milbank Quarterly, 2003, 81, 221-248.

Lee, A. Rigour and Relevance in MIS Research: Beyond the approach of positivism alone. MIS Quarterly, 1999, 23, 29-34.

Long Range Planning volumes 35-39.

Malhotra, N. The Nature of Knowledge and the Entry Mode Decision. Organization Studies, 2003, 24, 935-959.

Management International Review volumes 42-46. 
Matzler, K., Rier, M., Hinterhuber, H.H., renzl, B. and Stadler, C. Methods and concepts in management: significance, satisfaction and suggestions for further research perspectives from Germany, Austria and Switzerland. Strategic Change, 2005, 14, 1-13.

Munslow, A. What history is. History in Focus, 2001, 2, 1-6

Noblitt, G.W. and Hare, R.D Meta-ethnography: Synthesising Qualitative Studies. London, Sage Publications, 1988.

Phelan, S.E., Ferreira, M. and Salvador, R. The First Twenty Years of the Strategic Management Journal. Strategic Management Journal, 2002, 23, 1161-1168.

Podsakoff, P.M., MacKenzie, S.B., Bachrach, D.G. and Podsakoff, N.P. The Influence of Management Journals in the 1980s and 1990s. Strategic Management Journal, 2005, 26, 473-488.

Popper, K.R. The logic scientific discovery. London, Routledge, 1959.

Powell, T. The Philosophy of Strategy. Strategic Management Journal, 2002, 23, 873-880.

Powell, T. Strategy Without Ontology. Strategic Management Journal, 2003, 24, 285-291.

Quinton, S. and Smallbone, T. The troublesome triplets: issues in teaching reliability, validity and generalisation to business students. Teaching in Higher Education, 2005, 10, 299-311.

Raju, P.S., Lonial, S.C. and Mangold, W.G. Differential effects of subjective knowledge, objective knowledge, and usage experience on decision making: An exploratory investigation. Journal of Consumer Psychology, 1995, 4, 153-180.

Ramos-Rodriguez, A-R. and Ruiz-Navarro, J. Changes in the Intellectual Structure of Strategic Management Research: A bibliometric study of the Strategic Management Journal, 1980-2000. Strategic Management Journal, 2004, 25, 981-1004.

Ray, G., Barney, J.B. and Muhanna, W.A. Capabilities, Business Processes and Competitive Advantage: Choosing the dependent variable in empirical tests of the resource based view. Strategic Management Journal, 2004, 25, 23-37.

Reed, M. Reflections on the 'Realist Turn' in Organisation and Management Studies. Journal of Management Studies, 2005, 42, 1621-1644.

Rouse, M.J. and Daellenbach, U.S. More Thinking on Research Methods for the Resource Based Perspective. Strategic Management Journal, 2002, 23, 963-967.

Schreyogg, G. and Geiger, D. The Significance of Distinctiveness: A proposal for rethinking organizational knowledge. Organization, 2007, 14, 77-100.

$22,1-15$.

Shugan, S.M. Defining Interesting Research Problems. Marketing Science, 2003,

Smith, D.E. Ideology, Science and Social Relations: A reinterpretation of Marx's epistemology. European Journal of Social Theory, 2007, 7, 445-462.

Strategic Change volumes 11-15.

Strategic Management Journal volumes 23-27.

Strategic Organisation volumes 1-4.

Strategy and Leadership volumes 30-34.

Strategy and Leadership, 2004, 32, 27-33.

Straub, D., Boudreau, M-C. and Gefen, D. Validation Guidelines for IS Positivist Research. Communications of the Association of Information Systems, 2004, 1-70. 
Sutton, R.I. Prospecting for valuable evidence: why scholarly research can be a goldmine for managers. Strategy and Leadership, 2004, 32, 27-33.

Technology Analysis and Strategic Management volumes 14-18.

Teddlie, C. and Yu, F. Mixed Methods Sampling: A typology with examples. Journal of Mixed Methods Research, 2007, 1, 77-100.

Tranfield, D., Denyer, D. and Smart, P. Towards a methodology for developing evidence-informed management knowledge by means of systematic review. British Journal of Management, 2003, 14, 207-222.

Usunier, J-C. International and Cross Cultural Management Research. London, Sage Publications, 1998.

Vermunt, J. Conceptions of Research and Methodology Learning: A commentary on the special issue. Scandinavian Journal of Educational Research, 2005, 49, 329-334.

Yin, R. Mixed Methods Research: Are the methods genuinely integrated or merely parallel? Research in the Schools, 2006, 13, 41-47. 